\title{
Performance Study of Solar Adsorption Refrigeration System Using Activated Carbon - Methanol
}

\author{
Wissam H .Khaleel \\ Mechanical Eng. Dep., University \\ of Anbar, Al-Ramadi, IRAQ \\ wissam.gmw@uoanbar.edu.iq
}

Received: 02-Sep.-2018

Abdul Hadi N. Khalifa

Mechanical Eng. Dep., University of

Middle Technical, Baghdad, IRAQ

ahaddi58@yahoo.com

Revised: 06-Oct.-2018

Accepted: 14-Nov.-2018
Hilal Tareq Abdulazeez

Mechanical Eng. Dep., University

of Anbar, Al-Ramadi, IRAQ

helaltarik816@gmail.com

http://doi.org/10.29194/NJES.21040523

\begin{abstract}
The depleting of the conventional sources of energy and the excess use of HCF components lead to the need for new techniques both for conservation of energy sources for the future and for decreasing the its harmful effects on the environment. This study investigated the adsorption capabilities of activated carbon. The adsorption of methanol on this substance was tested for their application in the adsorption refrigeration system based on solar energy.

Adsorption refrigeration system has been designed and manufactured with the energy source being solar energy. Methanol/activated carbon pairs have been used in experiments. The present work focused on the performance of the adsorption refrigeration system considering the temperature attained in the evaporator and the cooled spaced cabinet. The amounts of activated carbon used was $(8 \mathrm{~kg})$, while the amount of methanol were $(1,1.25$, and 1.5$) \mathrm{kg}$. The experiments were done in different days of the year. The amount of adsorption of methanol (as a result of decreasing the evaporator and cooled spaced temperature) was found to depend on the generator pressure and its increase as the primary generator pressure decreases. The best mass of methanol used was $(1 \mathrm{~kg})$ which give the lowest temperature obtained at the evaporative surface was $\left(3.4^{\circ} \mathrm{C}\right.$ ) at the day ( 4/4/2017). The results shown that even in cloudy days there is a benefit from using such a system because the temperature attained is enough to start the adsorption process. The lowest temperature obtained at the evaporative surface was $\left(3.4{ }^{\circ} \mathrm{C}\right)$ at the day (4/4/2017) for methanol mass of $(1 \mathrm{~kg})$ at an opening time of the valve between the evaporator and the generator $(9: 30 \mathrm{am})$. The increase of methanol amount used in the experiment led to a good decrease in temperature attained in cooled spaced, but this is related to the time of connecting the evaporator and generator.
\end{abstract}

Keywords: Solar, Adsorption, Refrigeration, Methanol, Activated Carbon.

\section{Introduction}

In remote areas where the electrical power cannot be supplied easily, the use of the refrigeration and air conditioning may be restricted. Thus, it should be studied to find a new technique to develop an alternative power sources or even a new technology for the refrigeration and air conditioning fields. The alternative power sources could be the renewable energy, such as solar and wind energy. But, the use of the renewable energy sources should be connecting with a new design of the refrigeration system to be familiar with the new source of power. Thus, many new designs for the solar refrigeration systems are proposed around the world.

Solar cooling utilizes the solar radiation to power both the conventional and the new refrigeration systems. When the solar energy is used to power conventional systems, a set of batteries should be used to storage the solar energy in the form of electrical energy to overcome the shortage of solar radiation during night or cloudy days. While, the solar energy should be converted to heat to power the new refrigeration system design [1].

Adsorption Refrigeration, like the absorption refrigeration, is driven by thermal energy. In adsorption refrigeration, the traditional compressor is replaced by what is known as thermal compressor. The solar adsorption uses adsorption pairs that consist of the refrigerant, which is called the Adsorbate, while the substance that adsorbs the refrigerant is called the Adsorbent.

Solar energy is used to drive the solar refrigerator, in which the adsorption pair, such as, methanol - activated carbon is used. The methanol acts as refrigerant while the activated carbon is the adsorbent. Figure (1) shows the simple adsorption refrigerator. The refrigerator consists of a flat plate solar collector and a copper pipe filled with a granular activated carbon particle. The flat plate solar collector acts as unit generator. There is a manual valve that separates the generator from the other parts of the refrigerator. The condenser is used to condensate the methanol vapour. The condensate methanol is accumulated in the receiver. Finally, there is an evaporator in the form of thin metal box that is installed in the refrigerator case. 


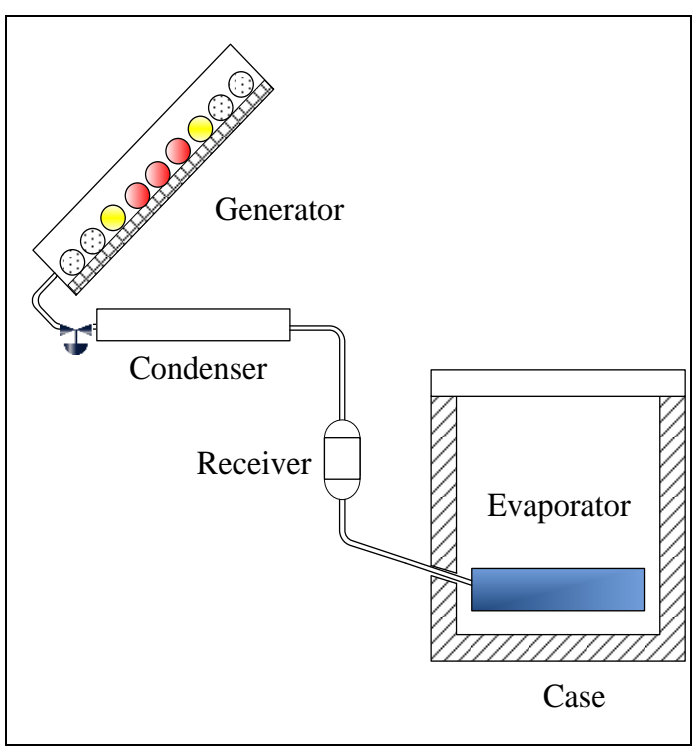

Figure 1: The simple adsorption refrigerator cycle.

The selection of adsorption pairs depends on the application of the adsorption refrigerator. Many considerations should be taken into account in selecting the adsorption pairs. The important consideration is the adsorption Ability [2]. Activated carbon - methanol is selected as an adsorption pair in the current work.

The adsorption refrigeration system was produced early in the beginning of the last century. In the 1920 s, G. E. Hulse suggested a refrigeration system where the working fluid is silica gel-SO2, this system was used for food products reservation in trains and coaches. Hulse et al. (1929) [3]. New technologies in the decade of $1930 \mathrm{~s}$, such as the discovery of the new refrigerant agent (Freon) and the effective creating of the compact closed compressor presented a good improvement to the performance of the compression refrigeration system remarkably. Due to these reasons the technology that depends upon adsorption refrigeration cycles could not challenge and compete with the highly efficient systems working on Carbon Flour Chlour refrigerants, such adsorbtion system had not taken considerable attention by researchers for a long time. The emergence of the problem of the ozone depletion and the Global warming effects pushed the world back to study the adsorption refrigeration, after a long time of abatement in this field.

Many researchers present studies that focus on behavior of adsorption solar refrigeration systems. Hildbrand et al. (2004) [4] developed an adsorption icemaker in which water was used as refrigerant and ice was produced within the evaporator.

Ammar S. (2006) [5] presented an experimental solar adsorption icemaker by using flat plate collector, where the same collector, beside it's working as generator also collect the solar radiation. The results was so promising.

Hassan J.(2008) [6] presented experimental and theoretical study of a hybrid adsorption refrigeration system tests in different of surrounding and generator temperature to obtained on the better result of (COP) was about 0.31 when the concentration of methanol in active carbon was 0.07 , surrounding temperature (22 $\left.{ }^{\circ} \mathrm{C}\right)$, generator temperature range about $\left(64{ }^{\circ} \mathrm{C}\right)$, minimum evaporator temperature was $\left(-1^{\circ} \mathrm{C}\right)$.

An air -conditioning unit based on adsorption thermodynamics cycle of two generator beds was designed and fabricated by Khalifa et al. (2015)[7]. The two beds were constructed from two concentric pipes made of copper. The bed generators were placed in a metallic pipe to transmit the exhausted hot gases, to construct double passages heat exchanger. For the completion of the air-conditioning system based on adsorption process, both the evaporator and the condenser were connected to the two bed generators. The exhaust gases in the system were created by burning hydrocarbon Propane gas. Results in this study presented the relation between the hot gases temperatures that was implemented to warm the bed generator, and the chilled water temperature was direct proportionality to the hot gases temperature. The least chilled water temperature achieved was (7.6 $\left.{ }^{\circ} \mathrm{C}\right)$. The fan coil unit system was supplied with chilled water to keep the indoor temperature at $\left(24.2^{\circ} \mathrm{C}\right)$ for a $(600 \mathrm{~W})$ air-conditioning space load. The highest value of the coefficient of performance of the cycle was about $(0.31)$ when the temperature of the hot gases was $\left(120^{\circ} \mathrm{C}\right)$.

The new adsorption system attracted Sah et al. (2016) [8]. They studied the adsorption process of an ice maker that may be used for storing perishable products. These ice maker machines take there required energy depending on solar radiation or depending on the waste heat recovery from automobile and industrial sectors. They presented the work both mathematically and experimentally. In spite of the fact that natural world benefits of such ice-maker machines are grand and wonderful, these refrigeration units have presented lower values of coefficient of performances with traditional types.

The operating and performance of an adsorption refrigeration system driven by a solar collector was investigated by Hadj Ammar, (2017)[9]. The thermodynamic cycle and the working principle of the system were based on the adsorption phenomena at a steady temperature. The system operated with activated carbon (AC)methanol as a working pair, and DubininAstakhov (D-A) formula was used to describe this phenomena. The comparative study between different types of $\mathrm{AC}$ revealed that the one based 
on stone coal had an optimal performance coefficient (COP) equal to 0.73 whereas a total energy input to the system is $18740.05 \mathrm{~kJ}$ and a total daily ice production of $13.65 \mathrm{~kg}$ at $-3{ }^{\circ} \mathrm{C}$. The studied case showed that the best performance of the system can be attained for low ambient and condensation temperature with high evaporation temperature. Ice produced can also be improved when the initial water temperature is low.

As mentioned later the main problems, which challenge the word recently, is that the lack of the traditional resources of energy and the depletion of Ozone layer and the global warming effects. This works aims to study the performance a simple size solar adsorption refrigerator. The characteristics of the performance of the solar refrigerator are studied under different operating parameters (including the operating conditions) and the mass of Methanol used.

There are extensive effort have been achieved in references [10-13] to develop the intermittent solid adsorption system that promises good choice as an alternative for solar refrigeration. Most research methods have used activated carbonmethanol for working pairs, and this has been considered as the most suitable working pair for solar solid adsorption Refrigeration. The solar energy is a renewable resource, clean and as mentioned later these systems considered environmentally friendly.

\section{Experimental Work}

A solar adsorption refrigerator that contains the following main components; two beds, condenser, receiver and evaporator which are built in the Engineering Technical College Baghdad, as shown in figure (2).

The generator acts as a thermal compressor and consists of two similar parts. Each one is built from galvanized steel channels, dimensions of $1170 \mathrm{~mm}$ length, $750 \mathrm{~mm}$ width and $60 \mathrm{~mm}$ height. Four fins of $1170 \mathrm{~mm}$ length, $18 \mathrm{~mm}$ width and $1.5 \mathrm{~mm}$ thickness are soldered through the channel. The aim of using fins is to prevent the channel from buckling since the generator operates at a pressure less than the environment pressure. The lower channel base is closed, while the upper one is provided by a header copper pipe of $9.525 \mathrm{~mm}$ diameter, many holes are drilled in the heater to penetrate the methanol vapour to the header. A steel mesh is used to cover the holes to prevent activated carbon from blocking the holes. The header is connected to two risers of diameter $9.525 \mathrm{~mm}$, each riser is supported by a manual valve. The headers are then collected in a single pipe that connects the two generators to the condenser inlet. Deep cleaning is achieved on the generator beds, and then each bed is filled with 8 $\mathrm{kg}$ of a cylindrical grain activated carbon of 3.5 $\mathrm{mm}$ in diameter, and ranging length from 5 to 15 $\mathrm{mm}$.

A natural air cooled wire condenser of 920 $\mathrm{mm}$ height is used to condensate the methanol vapour, the condenser is inclined by $15^{\circ}$ from horizontal to help the liquid methanol to flow to the receiver.

The receiver made of galvanized steel pipe of $900 \mathrm{~mm}$ length and $76.2 \mathrm{~mm}$ in diameter. The receiver is used to collect the liquid methanol after condenser. A galvanized steel box dimensions of $420 \mathrm{~mm}$ length, $300 \mathrm{~mm}$ width, and $30 \mathrm{~mm}$ depth is manufactured and acts as an evaporator. The evaporator is installed in a $5 \mathrm{ft}^{3}$ refrigerator body. A manual valve is used to separate the evaporator from receiver.

The two generators are installed in aluminum box with dimensions of $1280 \mathrm{~mm}$ length, $870 \mathrm{~mm}$ width and $140 \mathrm{~mm}$ depth. A sheet of glass of 6 $\mathrm{mm}$ thickness is used to cover the upper face of the box. Cork of $50 \mathrm{~mm}$ thickness is used to insulate the generators from sides, the all parts of system are installed as shown in figure (3).

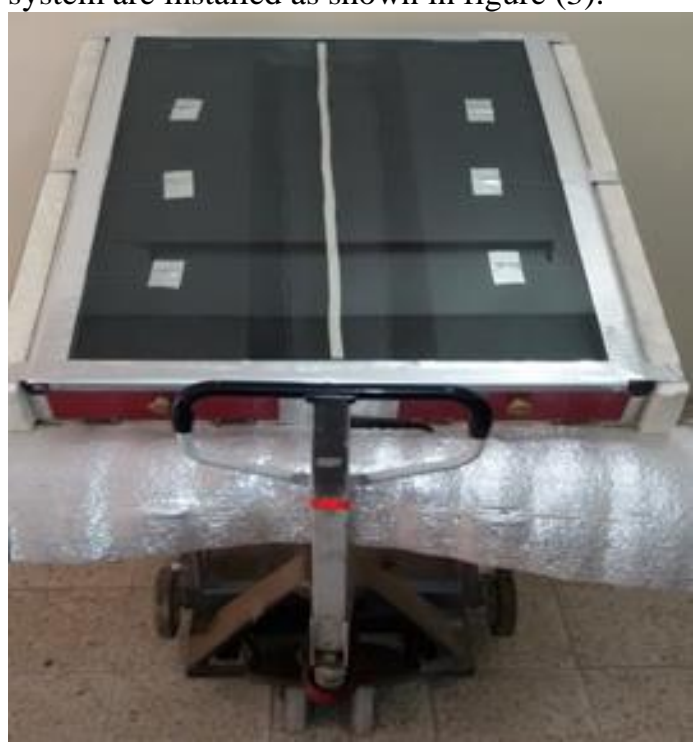

Figure 3: The adsorption refrigerator

\subsection{Experimental Procedure}

The experimental procedure was as follow:

- Charge the system with methanol, a cylinder filled with methanol of a given mass is connected through a manifold gauge and vacuum pump.

- The manifold gauges valves are opened and the vacuum pump is turned on to withdraw the air from the gauges hose for about three hours.

- All manifold valves are closed and the vacuum pump is turned off.

- A scale is used to measure the cylinder mass, and then the valve connecting the cylinder to the system is opened and the system is left for one day to allow the activated carbon to adsorb the methanol vapour. 
- When the system pressure is $(5 \mathrm{kPa})$, the valve is closed and takes the final mass of the cylinder.

- The difference between initial and final mass of the cylinder gives the mass of methanol charge, which equals about $(1.5 \mathrm{~kg})$. The charging process should be achieved in a shaded area.
- Measure temperature and pressure at all locations.

\subsection{Measuring and Instrumentation}

Many measuring meters and instruments are required to achieve a whole measurement to all variables in experiments.

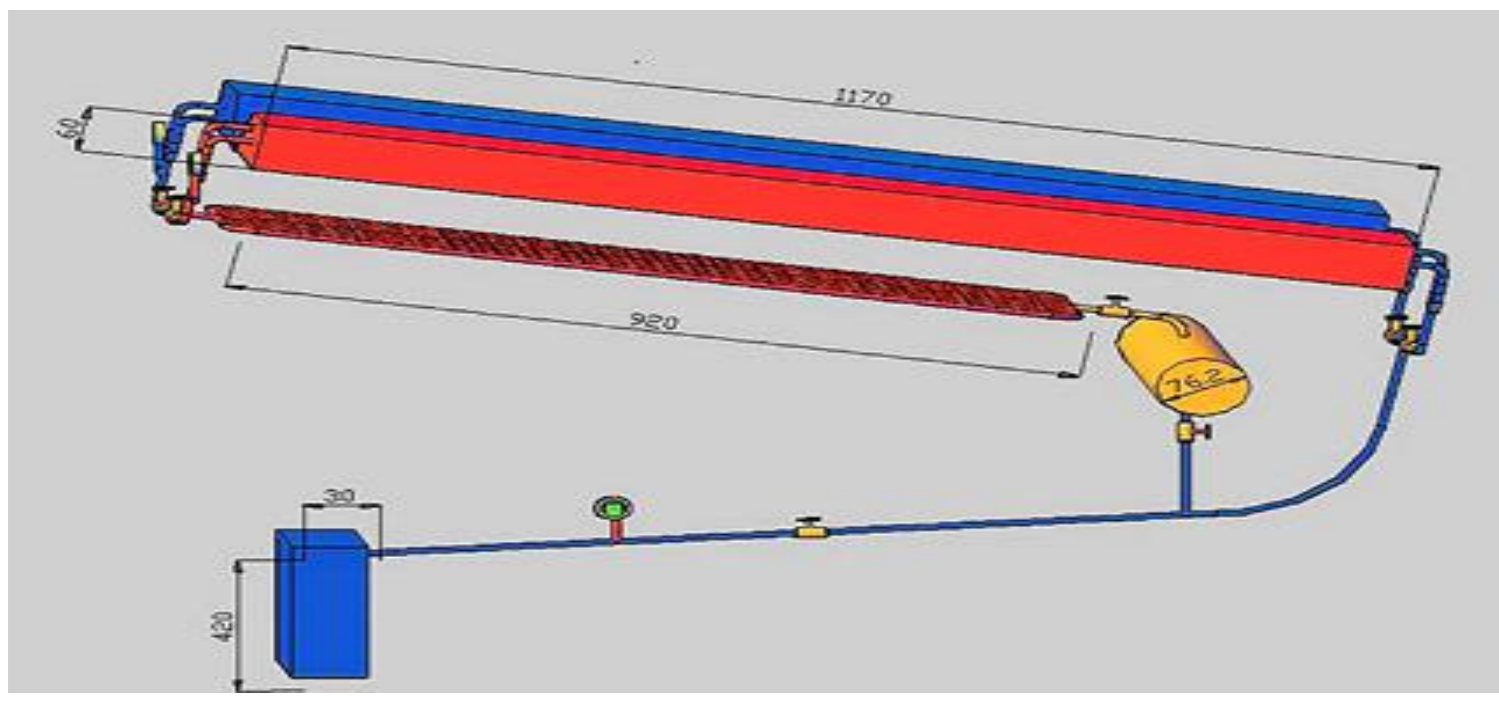

Figure 2: Schematic diagram of the solar adsorption cooling System

\subsubsection{Solar Insolation Measurement}

Solar power meter of type TES $1333 \mathrm{R}$ is used to measure the solar radiation in one hour steps, as shown in figure (4).

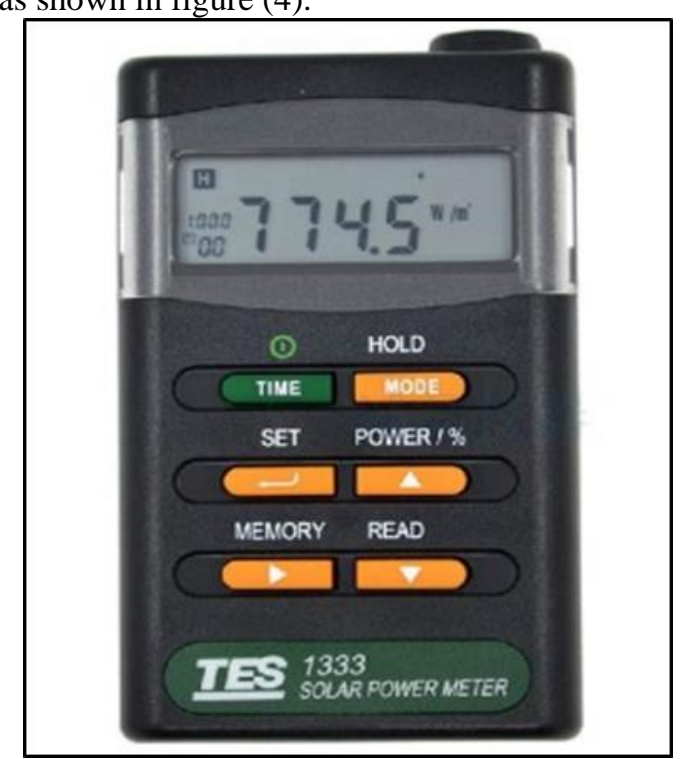

Figure 4: Solar meter Used in Experiments

\subsubsection{Pressure measurement}

Bourdon gauge is used to measure the pressure at condenser and evaporator. The gauges have a range of (0 to -100$) \mathrm{kPa}$ with an accuracy $\pm 0.1 \%$ of full scale, as shown in figure (5).

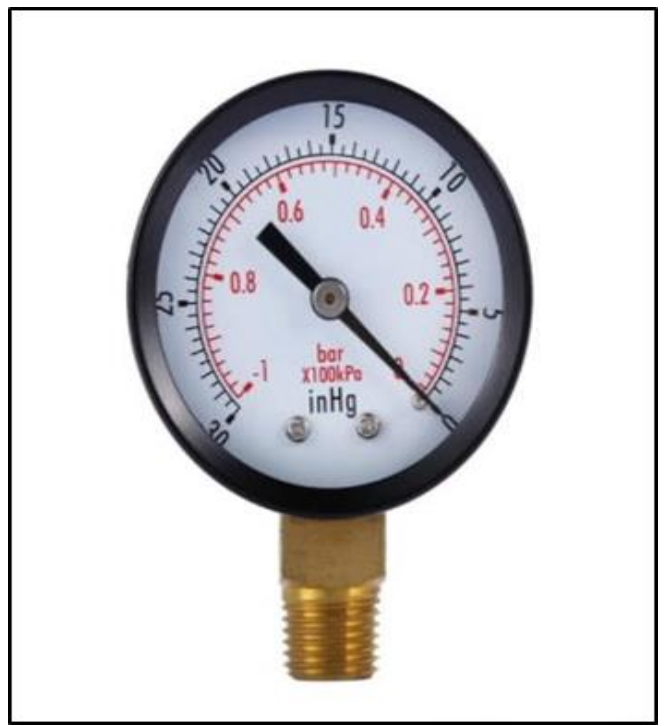

Figure 5: Pressure Gauges Used in Experiments

\subsubsection{Temperature measurement}

The temperatures at various points in the experiment are measured using LM35 sensors. All sensors were connected to a data acquisition system and interface card. The temperature is measured at 14 points, 6 of them are at the generator and other points distributed on different places of refrigerator, as shown in figure (6). The mentioned sensors were built in a microcontroller kits as a data aquestion, the LABVIEW program was used for measuring temperature. 


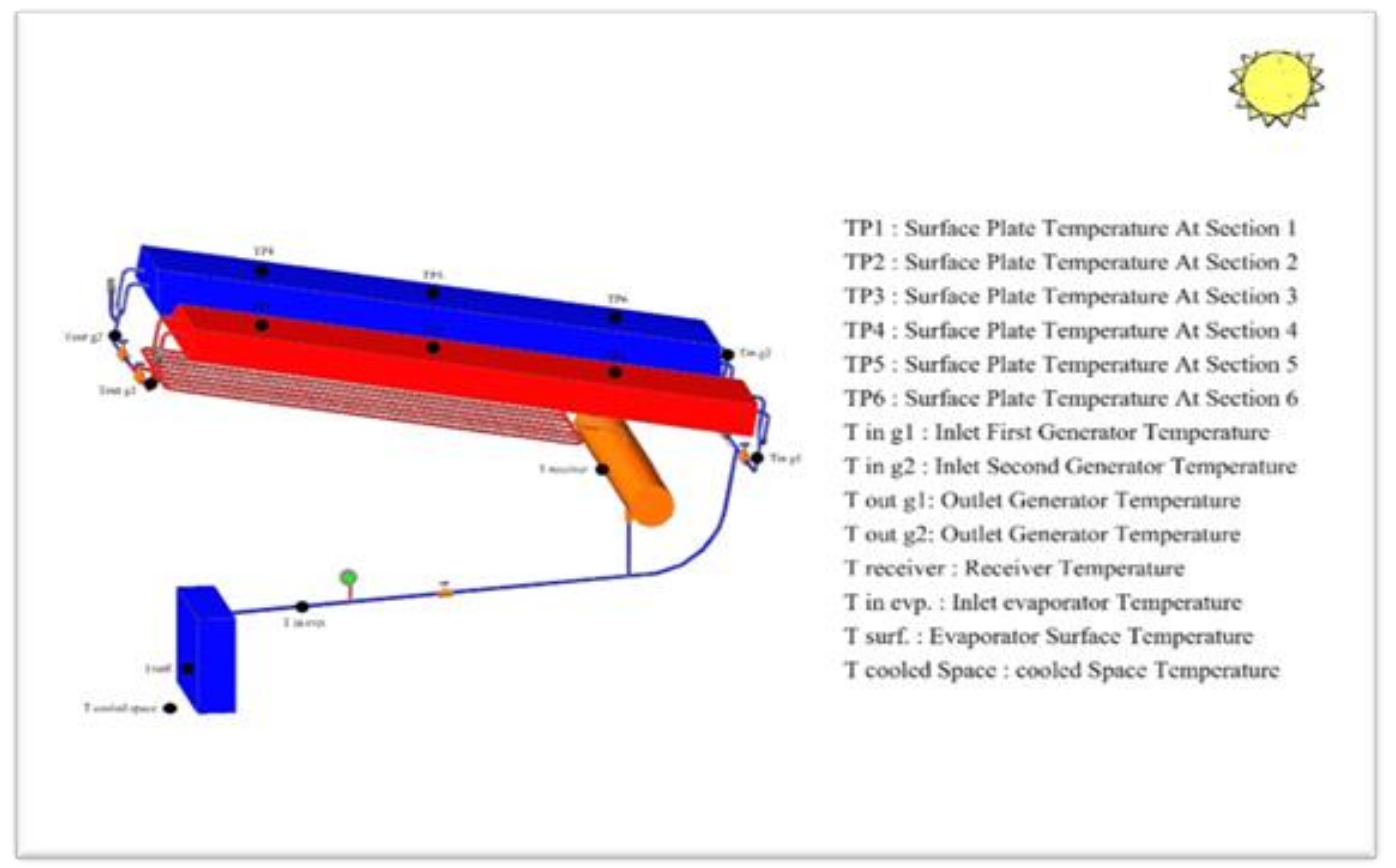

Figure 6: Location of the temperature measurement at the

\section{Results and Discussions}

The interest in adsorption cooling systems has been renewed in the last decades. The efficiency of such systems is greatly affected due the pairs used as working fluid and the operating conditions of the system. As was mentioned before, this work is for an adsorption cooling system with the aid of solar collector to achieve the necessary heating. In the experiments, the adsorbent used was $(8 \mathrm{~kg})$ of activated carbon as a physical adsorbent (generator), while the mass of the working fluid (refrigerant) is approximately $(1,1.25,1.5) \mathrm{kg}$ of pure Methanol. Tests were performed to determine the thermal behavior and cooling effect of adsorption system performance with these working fluids. These experimental tests cover the variation in the heating power (depending on the solar radiation for different days) and its effects on temperature and pressure distribution of adsorbent, condenser / evaporator of the adsorption system performance with time along the axial coordinate.

The effect of methanol mass and outdoor conditions on the performance of the solar adsorption refrigeration cycle are shown bellows, the experimental work is extended from 4/4/2017 to $17 / 4 / 2017$, where the mass of methanol were (1 $\mathrm{kg}$ and $1.25 \mathrm{~kg}$ ). For the period from (12/7/2016 to $13 / 7 / 2016)$ the mass of methanol was $(1.5 \mathrm{~kg})$.

The field system was tested on the circumstances of April month on the dates shown on each figures.

Figure (7) shows the behavior of solar radiation in the site of the field unit (Baghdad) on the generator surface. The amount of the methanol charged was $(1 \mathrm{~kg})$. The solar radiation increased from the beginning of the experiment at (10:00 am) and reached it is maximum value at (12:00 noon), then began to decrease to the end of the heating process of the collector at (12:00 pm).

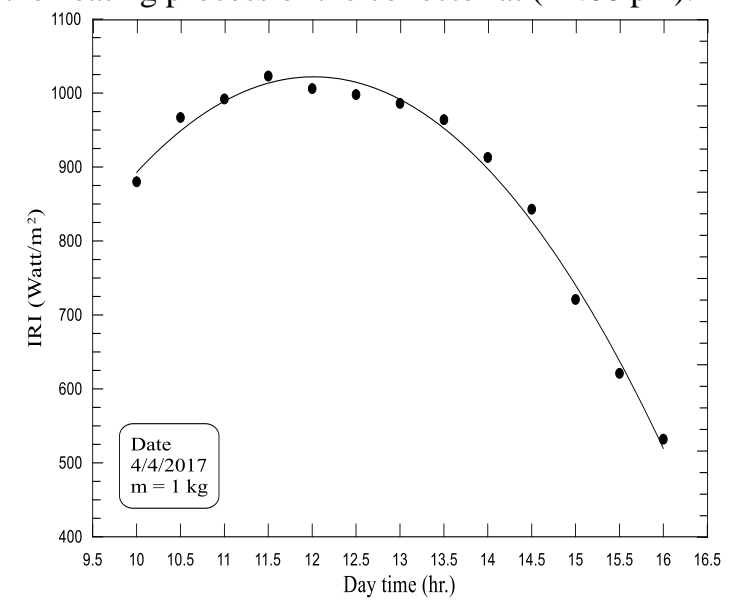

Figure 7: Solar radiation intensity on the unit generator.

The temperature of the surface of the collector was recorded and the average surface temperature with time is measured. The average temperature of the collector increased with the increase of the solar radiation and reached a maximum value of approximately $\left(94.5^{\circ} \mathrm{C}\right)$ as shown in Figure (8). 


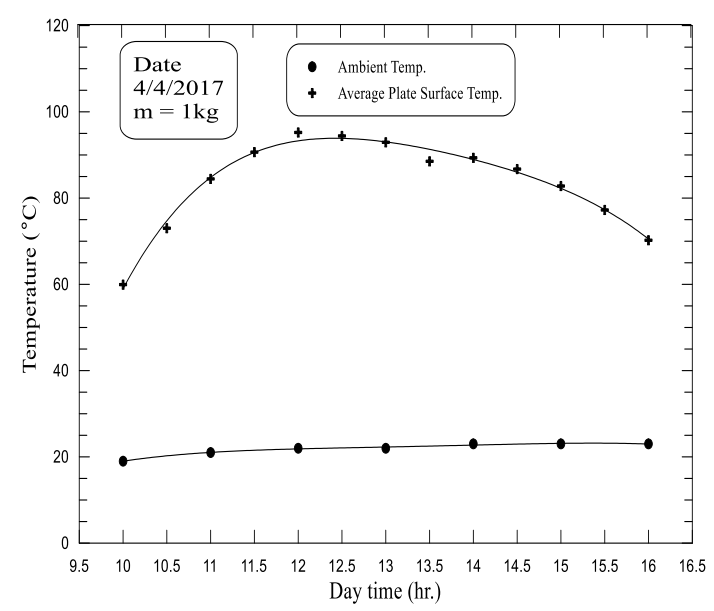

Figure 8: The variation of average plate temperature and ambient Temperature with the time.

Figure (9) shows the variation of generator pressure with time, when the mass of methanol is $(1 \mathrm{~kg})$, it can be seen from the figure that the initial generator pressure is about $(2 \mathrm{kPa})$, as the solar radiation covers the generator surface, the methanol desorb from the activated carbon and the pressure inside generator increases due to the increases of temperature due to the increase solar radiation. The maximum generator pressure reaches about $(35 \mathrm{kPa})$ at solar noon. Since the methanol mass is limited in the generator, thus the generator pressure increases rapidly. The valve isolated the generator from condenser is opened at $(12: 00 \mathrm{am})$, the generator pressure falls continuously until reaches about $(15 \mathrm{kPa})$ at time (16:00 pm).

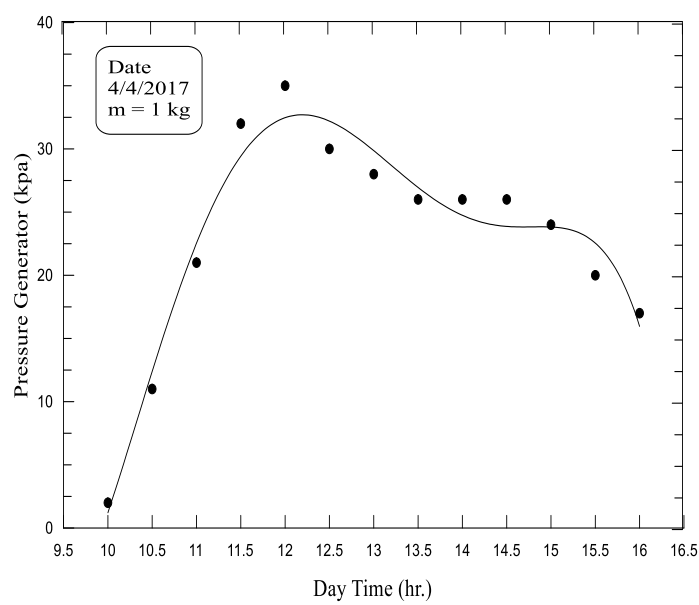

Figure 9: the variation of generator pressure with time.

The temperature at the outlet of the generator starting to increase till it reach to approximately $\left(41{ }^{\circ} \mathrm{C}\right)$ at noon as shown in Figure $(10)$, then as the valve opened the generator temperature falls less than a temperature of $\left(34^{\circ} \mathrm{C}\right)$ as shown in figure (4), as the sun set the generator temperature reduces.

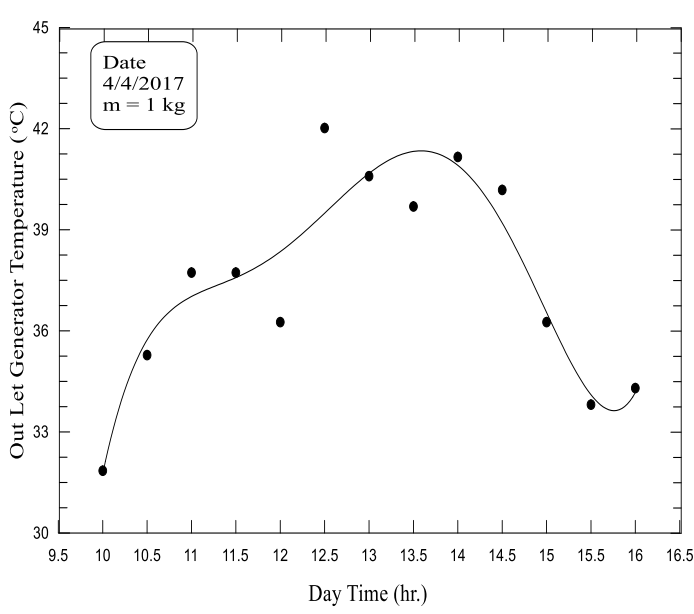

Figure 10: The variation of generator Temperature with the time.

Figure (11) shows the variation of evaporator inlet temperature and receiver temperature with the time, it can be seen from the figure that the receiver temperature increases with the increasing of the generator temperature, until it reaches the maximum temperature at time $(1: 30 \mathrm{pm})$. The evaporator inlet temperature is less than that of the receiver temperature, due to the heat lost to the ambient from the piping connecting the receiver to the evaporator.

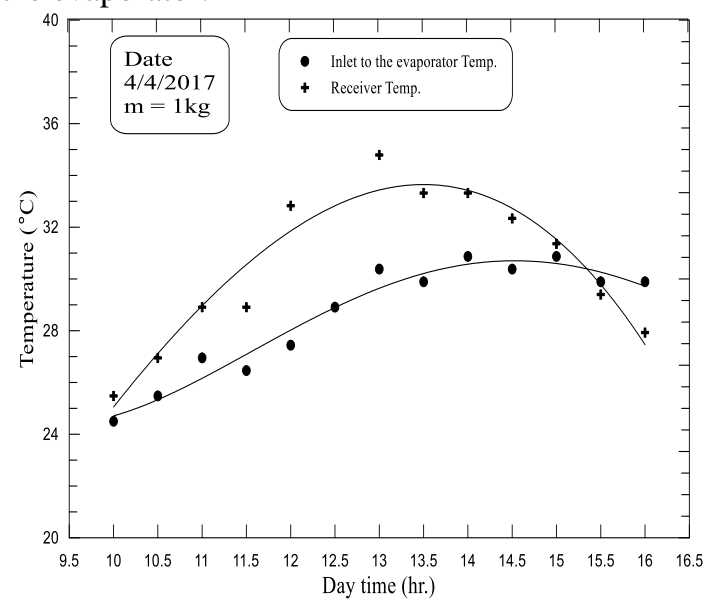

Figure 11: The variation of evaporator inlet temperature and receiver Temperature with the time

Figure (12) shows the variation of evaporator surface temperature and cold space temperature with the time. At early morning of the next day the liquid methanol is stored in the receiver, when the valve separated the receiver from the evaporator is opened the evaporator surface temperature falls suddenly from about 25 to about $3{ }^{\circ} \mathrm{C}$, at the same time the cold space temperature reduces from 24 to about $16{ }^{\circ} \mathrm{C}$, since the mass of methanol is enough to overcome the space load, thus the cooling process takes about only two hours from the open valve. 


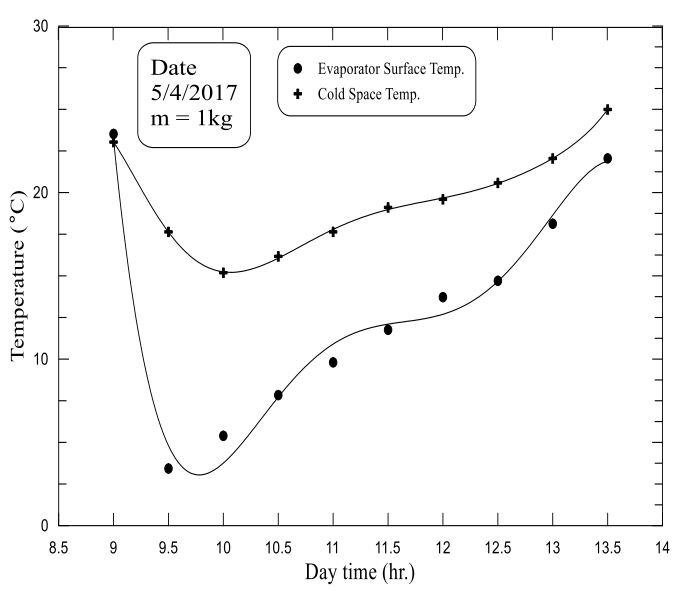

Figure 12: The variation of evaporator and cold space temperatues with the time.

Figure (13) shows the variation of the temperature of the evaporative surface temperature and average plate temperature with time. From figure it's noted that both temperatures are approximately same in the beginning of the day (5/4/2017), the temperature of the average plate of the cold space decreases from $\left(24^{\circ} \mathrm{C}\right)$ to $\left(4.9^{\circ} \mathrm{C}\right)$. This is due to the abrupt decrease in pressure for a short period which accompanied by a decrease in temperature due to the extracting of heat from the cooled space, During the evaporation of methanol and moving the methanol toward the generators accompanied by heat due to the adsorbtion process.

The mass of methanol is increased to $1.25 \mathrm{~kg}$ in the next step of experiment. Figures (14-20) shows the variation of mass of methanol on the parameters of the solar adsorption refrigerator. These figures show the same behavior as for $(1 \mathrm{~kg}$ of methanol) and the temperature of the evaporator surface fall down from $(21$ to 10$){ }^{\circ} \mathrm{C}$.

The effect of increasing methanol mass to (1.5 $\mathrm{kg}$ ) was studied as previous cases. These experiment were carried out at 13/7/2016. Even the weather was so hot, windy and dust, the evaporator surface temperature is decreased from $35^{\circ} \mathrm{C}$ to $15^{\circ} \mathrm{C}$, as shown in Fig.(21).

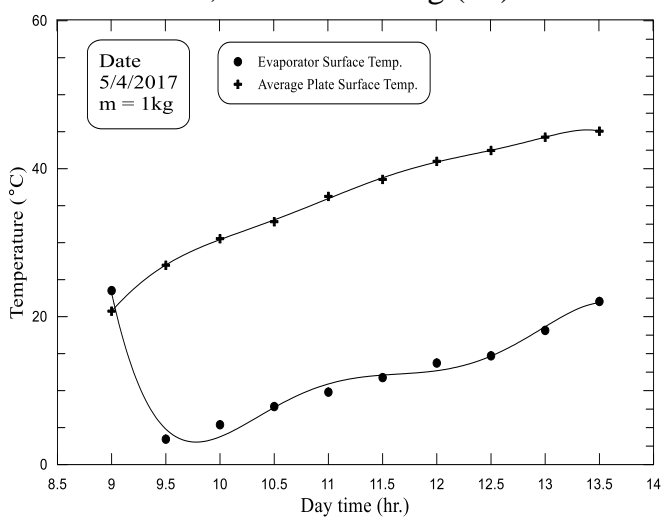

Figure 13: The variation of evaporator and average plate temperatures with the time.

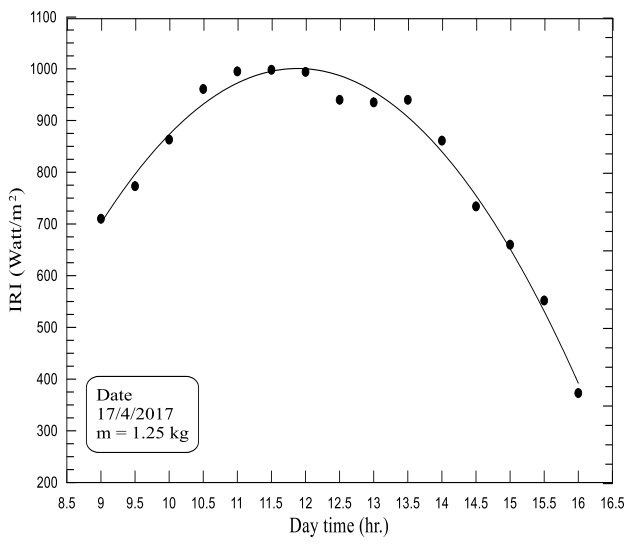

Figure 14: Solar radiation intensity on the unit generator.

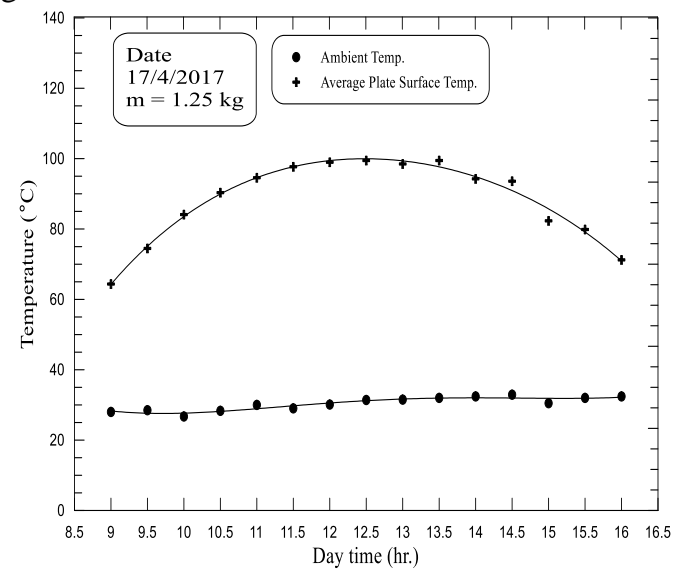

Figure 15: The variation of average plate temperature and ambient temperature with the time.

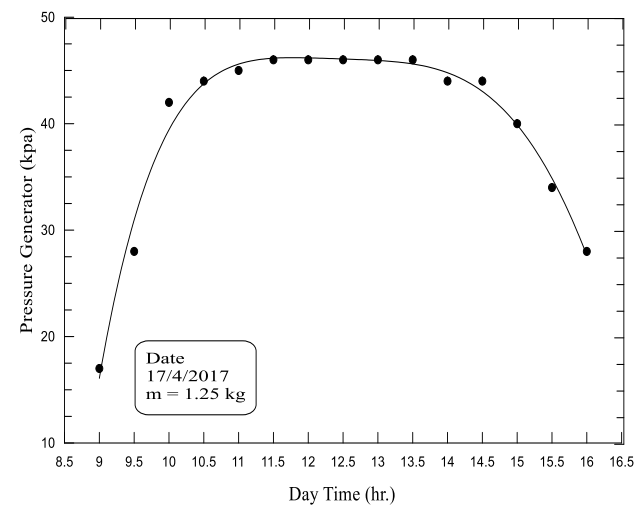

Figure 16: the variation of generator pressure with time. 


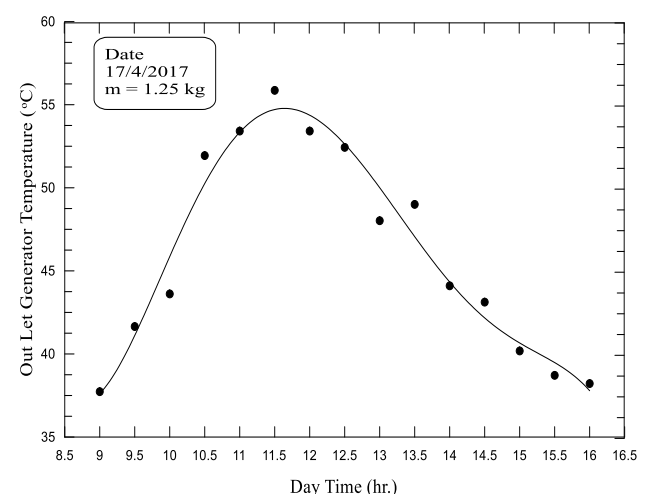

Figure 17: The variation of generator temperature with the time

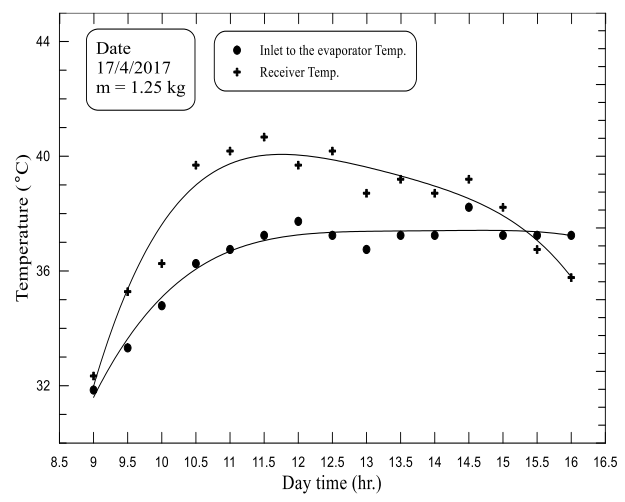

Figure 18: The variation of evaporator inlet temperature and receiver temperature with the time

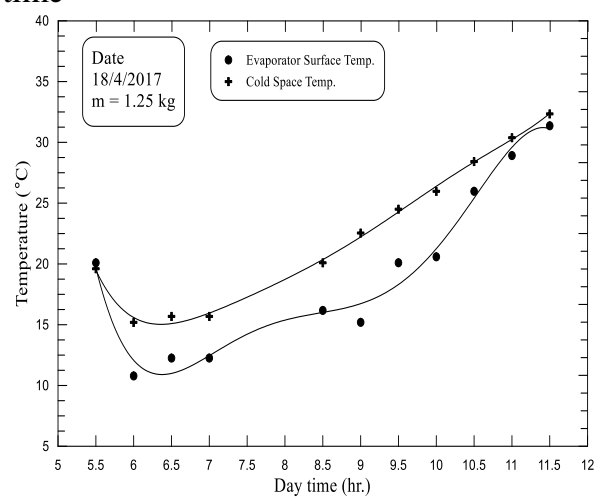

Figure 19: The variation of evaporator and cold space temperatures with the time.

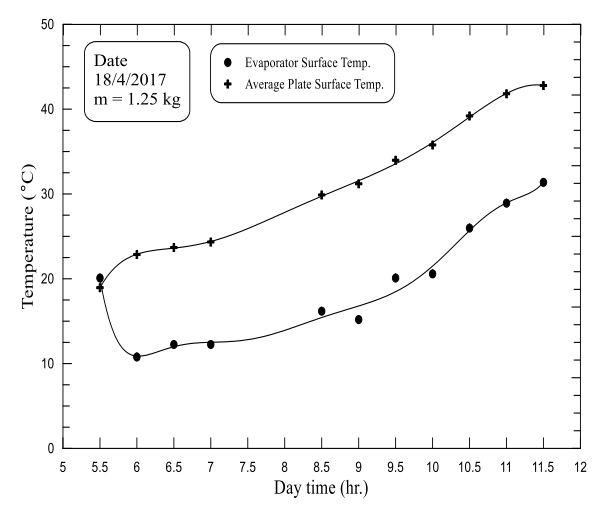

Figure 20: The variation of evaporator and average plate temperatures with the time.

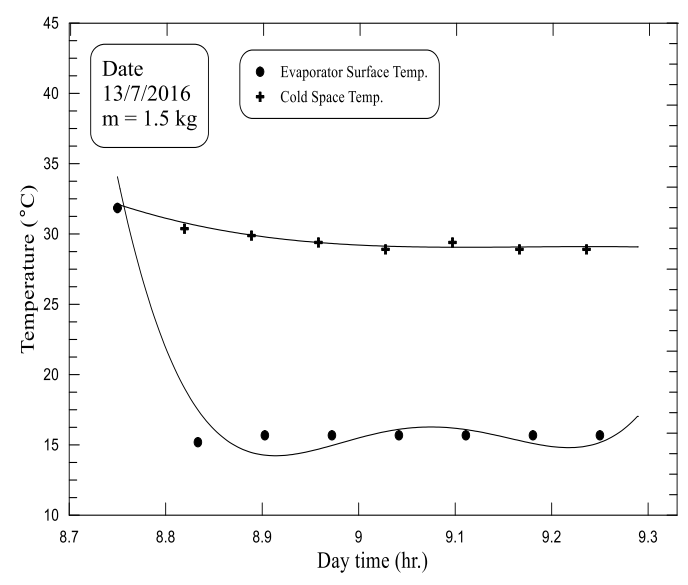

Figure 21: The variation of evaporator and cold space temperatures with the time

\section{Conclusions}

The study represents the use of adsorption refrigeration system with the aid of a solar collector to get the required energy for the adsorption process. This technique is widely used nowadays because of the decrease in conventional energy sources and the pollution taking place in the environment due to the use of Freon. The working of such systems gave many conclusions and these conclusions may be further studied to improve the performance of such system.

The main conclusions of the experimental results are as follows:

- It is shown that even in cloudy days there is a benefit from using such a system because the temperature attained is enough to start the adsorption process, The temperature difference obtained at April 2017 was $\left(\Delta \mathrm{T}=20^{\circ} \mathrm{C}\right)$, where the ambient temperature was $\left(24{ }^{\circ} \mathrm{C}\right)$. The temperature difference obtained at July 2016 was $\left(\Delta \mathrm{T}=16^{\circ} \mathrm{C}\right)$, where the ambient temperature was $\left(33^{\circ} \mathrm{C}\right)$.

- The lowest temperature obtained at the evaporative surface was $\left(3.4{ }^{\circ} \mathrm{C}\right)$ at the day (4/4/2016) for methanol mass of $(1 \mathrm{~kg})$ at an opening time of the valve between the evaporator and the generator (9:30 am).

- The increase of methanol amount used in the experiment led to a good decrease in temperature attained in cooled spaced, but this is related to the time of connecting the evaporator and generator.

- The wind is very affect in the performance of such a system due to the rapid cooling of the condenser.

- The coefficient of performance of the system is improved with the early connection between the evaporator and the solar collector bed. The best time to connect the evaporator to the solar collector is at the lowest temperature at the day. 


\section{References}

[1] R. Z. Wang and R.G. Oliveira, "Adsorption Refrigeration-an Efficient Way to Make Good Use of Waste Heat and Solar Energy", Progress in Energy and Combustion Science, vol. 32, pp. 424-458, 2006.

[2] Anyanwu, "Review of solid adsorption solar refrigerator I: an overview of the refrigeration cycle", Energy Conversion and Management , vol. 44, pp.301-312, 2003.

[3] Hulse, G. E." Freight Car Refrigeration by an Adsorption System Employing Silica Gel" Refrigerating Engineer 17(2): 41-54,1929.

[4] Hildbrand C, Dind P, Pons M, Buchter F. “ A new solar powered adsorption refrigerator with high performance". Sol Energy; 77(3):311-8, 2004.

[5] Ammar S. Abdul-Zahrah, " Design , Fabrication and Stydy of the Performance of an Icemaker Powered by Solar Energy", M.Sc. thesis, Mechanical Eng. Dept., Uni. of Technology, Baghdad, Iraq, 2006.

[6] Hassan Jawdat Fadiel, "Theoretical and Experimental Steady of a Hybird Adsorption Refrigeration System", M.Sc. Thesis, Dep. of Machines and Equipment - Uni. of Technology - Baghdad,Iraq, 2008.

[7] Khalifa, Abdul Hadi N., Ali H. Jabbar, and Jamal A. Muhsin "Effect of Exhaust Gas Temperature on the Performance of Automobile Adsorption Air-Conditioner" American Journal of Engineering and Applied Sciences 8(4): 575-581. 2015.

[8] Sah, Ramesh P., B. Choudhury, and Ranadip K. Das "A Review on Low Grade Heat
Powered Adsorption Cooling Systems for Ice Production" Renewable and Sustainable Energy Reviews 62: 109-120, 2016.

[9] Hadj Ammar, M. A., B. Benhaoua, and F. Bouras "Thermodynamic Analysis and Performance of an Adsorption Refrigeration System Driven by Solar Collector" Applied Thermal Engineering, 112: 1289-96. 2017.

[10] Alonso, L. Olivares de Lachica, E. Cardenas-Anaya, M. Marin-Becerril, J. Poblado-Barrales, X. Rebollo-Arana, Y. Gonzalez-Quezada " Solar Adsorption Refrigeration Using Methanol/Activated Charcoal", Proceedings of INTED 2012 Conference, At Valencia, Spain, Volume: ISBN: 978-84-615-5563-5 page 4571-78.

[11] Mohand Berdjaa, Brahim Abbada , Ferhat Yahia , Fateh Bouzefoura , Maamar Oualia "Design and realization of a solar adsorption refrigeration machine powered by solar energy", SHC 2013, International Conference on Solar Heating and Cooling for Buildings and Industry Sep. 23-25, 2013, Freiburg, Germany, Energy Procedia 48(2014)1226-35.

[12] Anan Pongtornkulpanich " Dynamic Simulation of Solid Adsorption Solar Refrigerator System with $\mathrm{AC} / \mathrm{CH} 3 \mathrm{OH}$ as a Working Pair", Energy and Power Engineering, 06(12), 2014.

[13] Himsar Ambarita, HidekiKawai, " Experimental study on solar-powered adsorption refrigeration cycle with activated alumina and activated carbon as adsorbent". Case Studies in Thermal Engineering, 7 (March), pp.36-46, (2016)

\section{دراسة اداء منظومة تبريد امتزازية شمسية باستخدام كاربون منشط - ميثانول}

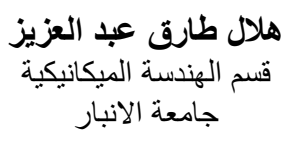

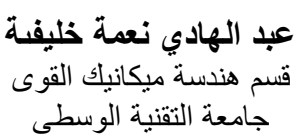

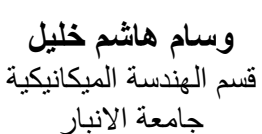

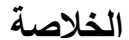

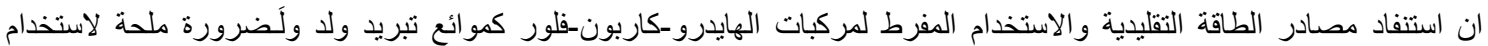

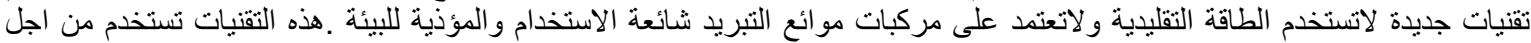

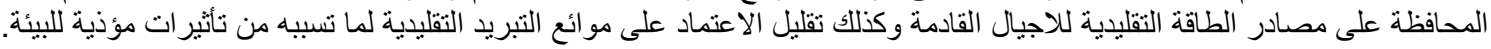

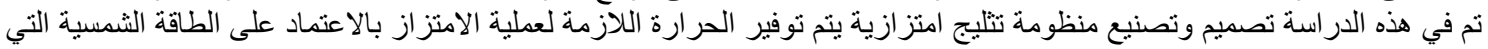

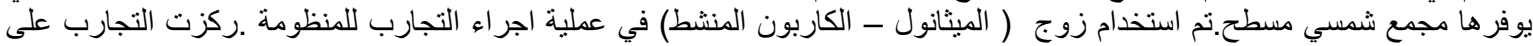

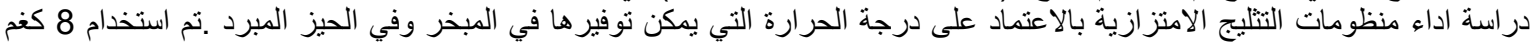

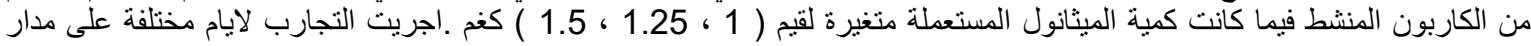

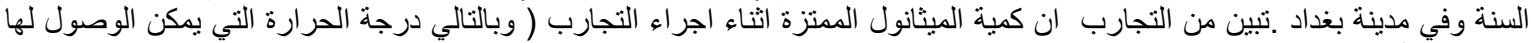

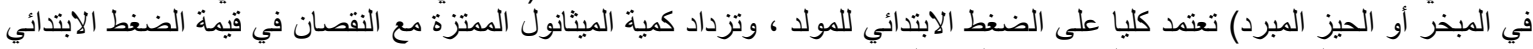

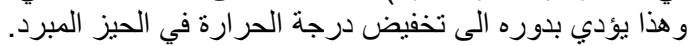

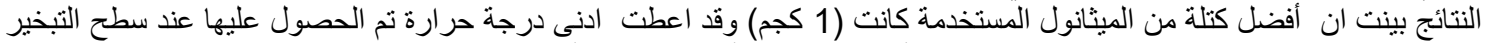

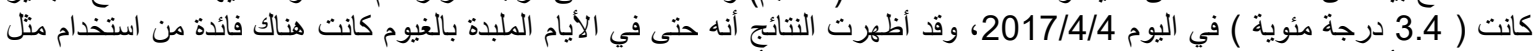

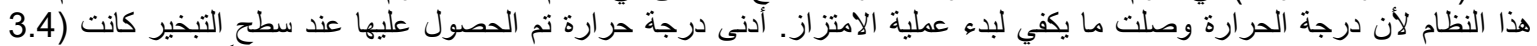

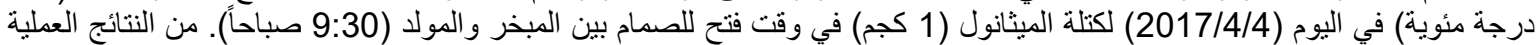

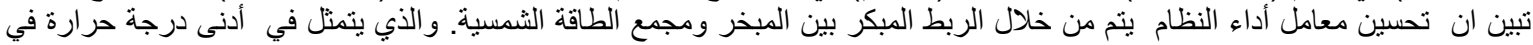
اليوم( درجة الحرارة الصغرى في اليوم ). 